\title{
PENGARUH KEPEMIMPINAN TRANSFORMASIONAL TERHADAP KOMITMEN ORGANISASIONAL MELALUI MEDIASI KEPUASAN KERJA
}

\author{
I Gusti Made Indra Bhaskara ${ }^{1}$ \\ Made Subudi ${ }^{2}$
}

\author{
${ }^{1,2}$ Fakultas Ekonomi dan Bisnis Universitas Udayana (Unud), Bali, Indonesia \\ E-mail: ibhas919@gmail.com
}

\begin{abstract}
ABSTRAK
Tujuan penelitian ini adalah untuk menganalisis pengaruh kepemimpinan transformasional terhadap kepuasan kerja dan komitmen organisasional, serta peran kepuasan kerja dalam memediasi kepemimpinan transformasional terhadap komitmen organisasional. Penelitian ini di lakukan di instansi Badan Pendapatan Daerah Provinsi Bali. Jumlah sampel yang diambil sebanyak 63 pegawai PNS Pengumpulan data dilakukan melalui wawancara terstruktur dan observasi. Teknik analisis yang di gunakan adalah analisis path. berdasarkan hasil analisis di temukan bahwa kepemimpinan transformasional berpengaruh positif dan signifikan terhadap kepuasan kerja, kepemimpinan transformasional berpengaruh positve dan signifikan terhadap komitmen organisasional, kepuasan kerja berpengaruh positive dan signifikan terhadap komitmen organisasional, serta kepuasan kerja dapat memediasi kepemimpinan transformasional terhadap komitmen organisasional. Saran yang dapat diberikan untuk instansi Badan Pendapatan daerah provinsi bali untuk menerapkan gaya kepemimpinan transformasional dengan baik untuk dapat meningkatkan kepuasan kerja pegawainya. Bagi Peneliti selanjutnya disarankan untuk menggunakan variabel lain yang dapat menjadi pemediasi antara kepemimpinan transformasional dan komitmen organisasional.
\end{abstract}

Kata kunci: kepemimpinan transformasional, kepuasan kerja, komitmen organisasional

\begin{abstract}
The purpose of this study was to analyze the effect of transformational leadership on job satisfaction and organizational commitment, as well as the role of job satisfaction in mediating transformational leadership on organizational commitment. This research was conducted at the Bali Provincial Revenue Agency. The number of samples taken was 63 goverment employees. Data collection was carried out through structured interviews and observations. The analysis technique used is path analysis. based on the analysis found that transformational leadership has a positive and significant effect on job satisfaction, transformational leadership has a positive and significant effect on organizational commitment, job satisfaction has a positive and significant effect on organizational commitment, and job satisfaction can mediate transformational leadership towards organizational commitment. Suggestions that can be given to the Agency of Bali's provincial Revenue Agency to apply transformational leadership style well to be able to increase employee job satisfaction. For further research it is recommended to use other variables that can be mediated between transformational leadership and organizational commitment.
\end{abstract}

Keywords: transformational leadership, job satisfaction, organizational commitment 
I Gusti Made Indra Bhaskara, Pengaruh Kepemimpinan Transformasional...

\section{PENDAHULUAN}

Sumber daya manusia pada suatu organisasi memiliki peranan penting, karena tanpa adanya dukungan sumber daya manusia yang baik maka suatu organisasi dapat menghadapi masalah dalam pencapaian tujuan organisasi (Ardana dkk, 2012:3). Dalam mengelola sumber daya manusia organisasi yang berada di dalam instansi pemerintahan harus dapat menciptakan suasana kerja yang kondusif dan nyaman agar dapat meningkatkan komitmen pegawai dalam berorganisasi. Suatu instansi tidak akan bisa mencapai target yang di inginkan apabila tidak ada komitmen dari pegawainya.

Kantor Badan Pendapatan Provinsi Bali beralamat di Jalan Tjok Agung Tresna No. 14. Merupakan intansi yang bergerak dibidang pendapatan daerah yang melaksanakan fungsi penunjang urusan pemerintahan yang menjadi kewenangan daerah provinsi di bidang keuangan sub pengelolaan pendapatan, serta melaksanakan tugas dekonsentrasi sampai dengan dibentuk sekretariat gubernur. Badan Pendapatan Daerah Provinsi Bali memiliki tujuan untuk terwujudnya pendapatan daerah secara optimal dalam rangka mendukung pembangunan daerah.

Hasil wawancara awal tersebut menunjukan bahwa terdapat permasalahan rendahnya komitmen organisasional pada 3 dimensi yaitu affective commitment, continuance commitment, normative commitment. Karena sebagian pegawai merasa masalah yang terjadi di instansi bukan menjadi permasalahan pribadi mereka sehingga para pegawai merasa tidak ada gangguan jika meninggalkan organisasi sehingga mudah bagi mereka untuk pindah ke biro-biro yang lain tanpa memikirkan organisasinya dan masih sangat rendahnya partisipasi pegawai dalam 
memajukan organisasi guna mencapai tujuan Komal (2011) Menyatakan komitmen organisasional dapat didefinisi sebagai afiliasi pegawai untuk organisasi dan keterlibatan di dalamnya yang secara umum terdiri dari tiga dimensi komitmen yaitu komitmen bersinambung, afektif, dan normatif. Lalu berdasarkan hasil observasi menemukan bahwa permasalahan terhadap komitmen organisasional yang di temukan adalah masih adanya pegawai yang belum memiliki komitmen yang tinggi dalam menjalankan tugas dan tanggung jawab mereka karena sebagian pegawai kurang berkomitmen dalam memajukan organisasinya. Mereka lebih cenderung untuk menyelesaikan suatu pekerjaan jika atasan sudah meminta hasil pekerjaannya dan dikerjakan dalam keadaan sudah mendesak dan hasilnya yang kurang maksimal yang di sebabkan oleh kurangnya motivasi dan perhatian terhadap fasilitas kerja yang di berikan oleh pimpinan karena belum maksimalnya penerapan gaya kepemimpinan transformasional pada Badan Pendapatan Daerah Provinsi Bali hal tersebut di khawatirkan mempengaruhi tujuan dari organisasi ini dimana tujuan dari Badan Pendapatan Daerah Provinsi Bali adalah Terwujudnya Pendapatan Daerah secara maksimal dan mampu merealisasikannya sesuai target yang telah di tentukan oleh pemerintah pusat. Berikut di sajikan data pendapatan daerah tahun 2015-2017:

Tabel 1.

Pendapatan daerah provinsi bali tahun 2015-2017

\begin{tabular}{cccc}
\hline Tahun & Keterangan & Pendapatan daerah $(\mathbf{R p )}$ & Persentase (\%) \\
\hline \multirow{2}{*}{2015} & Target & $4.900 .892 .440 .866,50$ & $101,37 \%$ \\
\multirow{2}{*}{2016} & Realisasi & $4.967 .919 .506 .470,72$ & \\
& Target & $5.218 .112 .635 .741,73$ & $100,59 \%$ \\
\multirow{2}{*}{2017} & Realisasi & $5.249 .015 .441 .333,80$ & \multirow{2}{*}{$96,11 \%$} \\
& Target & $6.222 .692 .203 .496,19$ & \\
\hline
\end{tabular}

Sumber: Badan Pendapatan Daerah Provinsi Bali, 2018 
I Gusti Made Indra Bhaskara, Pengaruh Kepemimpinan Transformasional...

Berdasarkan tabel 1 data pendapatan daerah pada badan pendapatan daerah provinsi bali tahun 2015-2017 mengalami penurunan realisasi dari tahun 2016 sampai dengan tahun 2017. Penurunan realisasi pada instansi Badan Pendapatan Daerah Provinsi Bali dalam 2 tahun terakhir cukup tinggi, mengingat target yang ditentukan oleh instansi sesuai dengan kebijakan Gubernur. Penurunan pendapatan daerah Jika dibiarkan terus menurun akan berdampak buruk bagi instansi, mengingat peraturan tersebut sudah dikaji sebelumnya dan harus terealisasikan.

Menurut Choong et al. (2012), pegawai yang berkomitmen untuk organisasi akan berupaya semaksimal mungkin dalam melaksanakan pekerjaannya. Namun jika pegawai yang memiliki komitmen yang rendah terhadap organisasi akan menghambat tercapainya tujuan organisasi. Menurut Azeem (2010) bahwa keberhasilan suatu organisasi dalam mengejar kualitas tidak hanya tergantung pada bagaimana organisasi mengembangkan kompetensi pegawainya, namun juga pada bagaimana organisasi meningkatkan komitmen dari anggota organisasinya, baik komitmen pada pekerjaan maupun pada arahan atasan. Wibawa (2015) mengatakan bahwa komitmen organisasi adalah hal yang berharga untuk seluruh organisasi, dan bukan hanya untuk pekerjaan, maupun kelompok kerja. Komitmen pegawai sendiri bersifat relative dari individu dalam mengidentifikasikan keterlibatan dirinya ke dalam bagian organisasi itu sendiri. Mohamed (2012) mengatakan bahwa komitmen organisasional melihat kepada kesiapan pegawai untuk bekerja keras, menerima dan mewujudkan tujuan organisasi, standar organisasi, prinsip organisasi, etika organisasi dan nilai-nilai organisasi untuk tetap bertahan pada organisasi dalam segala bentuk situasi dan kondisi organisasi. Nawab dan Djastuti 
(2011) mengemukakan bahwa komitmen organisasional dapat mendorong kebiasaan dari para pegawai untuk bekerja lebih efektif, ketika pegawai sudah memiliki komitmen organisasional yang tinggi akan berorientasi pada pekerjaan.

Dalam meningkatkan komitmen organisasi para pegawai, tidak lepas dari gaya kepemimpinan yang di terapkan, dimana arti dari kepemimpinan adalah upaya seseorang dalam mempengaruhi orang lain agar bertindak sesuai dengan yang di inginkan olehnya. Humphrey (2012) menyebutkan bahwa pemimpin memiliki kekuatan langsung yang memiliki efek luar biasa terhadap para pengikut. Dalam rangka mempengaruhi orang lain, seorang pemimpin mempunyai banyak pilihan gaya kepemimpinan yang akan digunakannya. Salah satu gaya kepemimpinan yang paling sering di terapkan adalah kepemimpinan transformasional. Yu Bo (2013) mengemukakan bahwa pemimpin transformasional dapat membuat pegawai percaya dan menghormati atasan mereka. Tuna et al. (2011) menyatakan bahwa kepemimpinan transformasional dapat meningkatkan komitmen dan loyalitas pegawai terhadap instansi. Dunn et al. (2012) menyatakan bahwa pemimpin dengan gaya transformasional mampu memahami kebutuhan bawahan, memberi perhatian dan dukungan terhadap bawahan, bertindak sebagai mentor yang membimbing bawahan untuk mencapai prestasi kerja sehingga akan berdampak pada meningkatnya komitmen organisasional. Faharani et al. (2011) Menyatakan Pemimpin yang memiliki sifat pemimpin tranformasional dapat menginspirasi dengan memberikan motivasi agar pegawai lebih berprestasi dalam pekerjaannya, sehingga hal tersebut memperkuat komitmen organisasi. 
I Gusti Made Indra Bhaskara, Pengaruh Kepemimpinan Transformasional...

Pegawai yang memiliki komitmen organisasi yang tinggi dapat dilihat dari kepuasan kerjanya dalam berorganisasi. Srivastava (2013) Kepuasan Kerja merupakan sikap (positif) tenaga kerja terhadap pekerjaannya, yang timbul berdasarkan penilaian terhadap situasi kerja. Penilaian tersebut dapat dilakukan terhadap salah satu pekerjaan yang dilakukan oleh pegawai, penilaian dilakukan sebagai rasa menghargai dalam mencapai salah satu nilai-nilai penting dalam pekerjaan. Permadi (2017) mengemukakan bahwa kepuasan kerja (job statification) adalah wujud dari persepsi pegawai yang tercermin dalam sikap dan fokus pada perilaku pekerjaan. Ini juga merupakan suatu bentuk interaksi antara manusia dengan lingkungan pekerjaannya, Selain itu dalam bekerja ditunjukkan dengan adanya gairah dan semangat kerja, disiplin dan sebagainya.Sakirui et al. (2013) berpendapat bahwa dengan terciptanya kepuasan kerja dalam suatu perusahaan akan berdampak pada meningkatnya gairah kerja. Kepuasan kerja yang tinggi akan menandakan bahwa organisasi telah dikelola dengan baik dan dengan manajemen yang efektif. Rae (2013) dalam penelitiannya mengatakan kepuasan kerja adalah bagian penting dari pengalaman hidup pegawai dalam bekerja, artinya terkait dengan seorang pegawai menerima cukup imbalan mendorong pegawai untuk tetap ditempat kerja mereka dan terus menghabiskan sebagian besar waktu untuk pemenuhan tugasnya. Aydogdu dan Asikgil (2011) dalam penelitiannya menyatakan bahwa semakin tinggi kepuasan kerja maka komitmen organisasional akan semakin meningkat pula. Kesuma (2016) penelitiannya menyatakan untuk meningkatkan komitmen pegawai dalam penerapan gaya kepemimpinan 
transformasional harus meningkatkan kepuasan kerja dulu sehingga dapat meningkatkan komitmen organisasi.

Kepemimpinan Transformasional adalah suatu model kepemimpinan untuk meningkatkan sumberdaya manusia dengan dan hubungan efek pemimpin terhadap bawahan dapat diukur, dengan indikator adanya kepercayaan, kekaguman, kesetiaan, dan hormat terhadap pemimpin, berusaha untuk memotivasi pengikut untuk melakukan sesuatu yang lebih dan melakukannya melampaui harapan mereka sendiri Bass (1994). Kepemimpinan transformasional, digambarkan sebagai gaya kepemimpinan yang dapat membangkitkan atau memotivasi pegawai, sehingga dapat berkembang dan mencapai kinerja pada tingkat yang tinggi, melebihi dari apa yang mereka perkirakan sebelumnya (Yukl, 2010:303). Kepemimpinan transformasional mengevaluasi kemampuan dan potensi masing-masing bawahan untuk menjalankan suatu tugas/pekerjaan, sekaligus melihat kemungkinan untuk memperluas tanggung jawab dan kewenangan bawahan di masa mendatang (Maulizar dkk., 2012).

Pada tahun 1973, Downtown mencetuskan istilah kepemimpinan transformasional yang berarti sebuah proses dimana di dalamnya orang-orang mengalami perubahan baik emosi, nilai, etika, standar, maupun tujuan mereka (Northouse, 2013:176). Menurut Warrick (2011) kepemimpinan transformasional lebih memfokuskan pada kemampuan kepemimpinan dan membawa kepemimpinan ke tingkat yang baru. Keberadaan pemimpin memegang peranan penting dalam suatu organisasi. Peran seorang pemimpin adalah sebagai penunjuk 
I Gusti Made Indra Bhaskara, Pengaruh Kepemimpinan Transformasional...

arah dan tujuan di masa depan (direct setter), agen perubahan (change agent), negosiator (spokes person), dan sebagai pembina (coach) (Munawaroh, 2011).

Surbakti (2013) mengemukakan bahwa interaksi yang dimiliki antara pemimpin yang memiliki gaya kepemimpinan transformasional dengan bawahannya ditandai dengan besar atau kecilnya pengaruh yang diberikan oleh pemimpin terhadap bawahannya untuk berubah. Shahhosseini et al. (2013) berpendapat seorang pemimpin dengan mempraktikan gaya kepemimpinan transformasional memiliki peran utama dalam mempengaruhi perubahan yang cepat dan memotivasi pegawainya untuk meningkatkan pengetahuan mereka mengenai instansi di tempat mereka bekerja, serta mengubah keyakinan para pegawai kearah yang lebih baik. Cavazotte et al. (2012), pemimpin transformasional memiliki kecerdasan dan kepribadian yang dimana menimbulkan pengaruh langsung maupun tidak langsung melalui komunikasi mereka dengan pegawainya.

Berdasarkan pendapat para ahli tersebut, maka dapat dikemukakan bahwa kepemimpinan transformasional merupakan pemimpin yang dapat menginspirasi para bawahannya untuk mengenyampingkan kepentingan pribadi mereka demi kebaikan organisasi dan mereka mampu memberikan pengaruh yang luar biasa.

Faharani et al. (2011) membuktikan bahwa terdapat hubungan langsung dan positif antara kepemimpinan transformasional dengan komitmen organisasional. Yang (2012) menemukan bahwa dimensi kepemimpinan transformasional memiliki pengaruh yang signifikan terhadap kepuasan kerja dan komitmen organisasional. Mohammad (2012) menyatakan bahwa gaya kepemimpinan 
transformasional secara signifikan berkorelasi dengan komitmen organisasional. Hasil penelitian yang dilakukan oleh Dunn et al. (2012) terhadap organisasi di AS dan Israel memberikan bukti yang mendukung bahwa perilaku pemimpin transformasional secara signifikan dan positif berhubungan dengan komitmen organisasional. Tuna et al. (2011) melakukan penelitian pada industri rumah sakit di Turki dan menyimpulkan bahwa kepemimpinan transformasional meningkatkan komitmen dan loyalitas pegawai terhadap organisasi.

$\mathrm{H}_{1}$ : Kepemimpinan transformasional berpengaruh positif dan signifikan terhadap komitmen organisasional

Judge dan Locke (1993) menegaskan bahwa gaya kepemimpinan merupakan salah satu faktor penentu kepuasan kerja. Jika seorang pemimpin menerapkan gaya kepemimpinan yang mampu menciptakan suasana kondusif makadapat mendorong tingkat kepuasan kerja seorang pegawai, pegawai akan merasa menjadi lebih nyaman. Al-Swidi et al. (2012) menyatakan bahwa kepemimpinan transformasional telah terbukti memiliki pengaruh positif signifikan pada kepuasan kerja pegawai melalui peningkatan persepsi pemberdayaan pegawai. Zahari dan Shurbagi (2012) melakukan penelitian terhadap pegawai dari National Oil Corporation Libya. Hasil penelitiannya menunjukkan hubungan positif yang signifikan antara gaya kepemimpinan transformasional dengan kepuasan kerja pegawai. Athanasios dan Belias (2014) juga mengatakan bahwa kepemimpinan transformasional berpengaruh positif terhadap kepuasan kerja. Yang dan Islam (2012) melakukan penelitian untuk menunjukkan pengaruh kepemimpinan transformasional terhadap kepuasan kerja dengan menggunakan perspektif bisnis dari balanced scorecard, dan menunjukkan hasil yang positif dan signifikan. 
I Gusti Made Indra Bhaskara, Pengaruh Kepemimpinan Transformasional...

$\mathrm{H}_{2}$ : Kepemimpinan transformasional berpengaruh positif dan signifikan terhadap kepuasan kerja

Aydogdu dan Asikgil (2011) dalam penelitiannya menyatakan bahwa ada hubungan yang signifikan dan positif antara kepuasan kerja dan komitmen organisasional. Hasil penelitian Srivastava (2013) yang menyatakan bahwa kepuasan kerja dan komitmen organisasi berhubungan positif. Oyewobi et al. (2012) pada penelitian quantity surveyor dalam pelayanan public nigeria menunjukan bahwa korelasi positif yang kuat memang ada antara variabel kepuasan kerja dengan komitmen organisasional. Fu et al. (2011), menyimpulkan bahwa aspek kepuasan kerja yaitu gaji, rekan kerja, supervisi, promosi dan pekerjaan itu sendiri memiliki dampak yang signifikan terhadap komitmen organisasional. Adekola (2012) dalam penelitiannya menyatakan bahwa ada hubungan positif yang signifikan antara kepuasan kerja dan komitmen organisasi. Tingkat yang lebih tinggi dari komitmen antara pegawai pasti akan menghasilkan tingkat lebih tinggi dari kepuasan kerja antara pegawai.

$\mathrm{H}_{3}$ : Kepuasan kerja berpengaruh positif dan signifikan terhadap komitmen organisasional

Berdasarkan penelitian yang dilakukan oleh Aydogdu dan Asikgil (2011) meneliti hubungan antara variabel kepuasan kerja dan komitmen organisasional, yang membuktikan bahwa kepuasan kerja memiliki hubungan yang signifikan dan positif terhadap tiga dimensi komitmen organisasional, yaitu komitmen afektif, komitmen berkelanjutan, dan komitmen normatif. Hubungan positif moderat signifikan juga ditemukan antara aspek kepuasan kerja, faktor demografi, dan komitmen organisasional pada penelitian yang dilakukan oleh Azeem (2010). Hasil 
penelitian Joo et al. (2012) yang menemukan fakta bahwa indikator kepemimpinan transformasional yang meliputi artikulasi visi, dan stimulasi intelektual adalah prediktor yang signifikan untuk komitmen organisasional. Melalui dukungan individual, pemimpin transformasional menghormati pengikut mereka dan memahami perasaan dan kebutuhan pribadi, sehingga pengikut akan lebih terlibat dan setia. Voon (2011) yang menyatakan bahwa kepemimpinan yang bergaya transformasional memiliki pengaruh positif terhadap kepuasan kerja pegawai Menurut Kesuma (2016) menyatakan bahwa kepuasan kerja memediasi kepemimpinan trasfomasional terhadap komitmen organisasional berdasarkan penelitian sebelumnya maka dapat diambil hipotesis sebagai berikut

$\mathrm{H}_{4}$ : kepuasan kerja memediasi kepemimpinan transformasional terhadap komitmen organisasional

\section{METODE PENELITIAN}

Berdasarkan permasalahan yang terdapat dalam penelitian ini, desain penelitiannya digolongkan pada jenis penelitian asosiatif (hubungan) karena dalam penelitian ini mempunyai tujuan untuk mengetahui pengaruh sebab akibat dari variabel-variabel yang diteliti (Sugiyono, 2013:5). Variabel yang diteliti dalam penelitian ini adalah gaya kepemimpinan transformasional sebagai variabel bebas (X), kepuasan kerja sebagai variabel mediasi (M), serta komitmen organisasi sebagai variabel terikat (Y).

Lokasi penelitian ini dilakukan di Badan Pendapatan Daerah Provinsi bali yang berlokasi di Jl cok agung tresna no 14, Renon Denpasar. Tempat ini dipilih sebagai lokasi penelitian karena belum banyak yang melakukan penelitian di instansi pemerintahan tersebut mengenai sumber daya manusianya, dan diduga 
I Gusti Made Indra Bhaskara, Pengaruh Kepemimpinan Transformasional...

terdapat masalah yang menyangkut komitmen organisasi di Badan pendapatan daerah provinsi bali.

Populasi dalam penelitian ini adalah seluruh pegawai pada Badan Pendapatan Daerah Provinsi Bali kecuali kepala badan dan kepala sub-sub bagian yang ada pada instansi karena dalam salah satu variabel mengenai kepemimpinan. Jumlah populasi pada penelitian ini adalah 167 pegawai PNS. Sampel yang di pilih dalam penelitian ini menggunakan teknik purposive sampling yaitu teknik penentuan sampel dengan pertimbangan tertentu

Prosedur penentuan jumlah sampel pada penelitian ini menggunakan rumus slovin dengan tingkat kesalahan $(\alpha)$ sebesar $10 \%$ penggunaan derajat $10 \%$ dimaksudkan agar penelitian yang dilakukan ini menjadi lebih efektif. Sampel yang akan diteliti dengan dasar perhitungan pada jumlah populasi Pegawai Badan Pendapatan Daerah Provinsi Bali adalah sebagai berikut:

$\frac{\mathrm{N}}{N \cdot d^{2}+1}$

Dimana :

$\mathrm{n}=$ Jumlah sampel

$\mathrm{N}=$ Jumlah populasi

$\mathrm{d}=$ Persentase kelonggaran kesalahan pengambilan sampel yang masih dapat ditolerir, dalam penelitian ini digunakan persentase kesalahan $10 \%$.

Besarnya populasi yaitu sebesar 167 orang. Jadi besarnya sampel yang harus dicapai dalam penelitian ini adalah sebesar :

$$
n=\frac{\mathrm{N}}{N \cdot d^{2}+1}=\frac{1}{\left(1 \quad .0,1^{2}\right)+1}=\frac{1}{2,6}=62,54=63
$$


Berdasarkan rumus slovin di atas, sampel yang dapat di ambil dari populasi yang besar yaitu sebanyak 62,54 orang karena sampel dalam penelitian ini adalah pegawai maka jumlah sampel di bulatkan menjadi 63 responden.

Penelitian ini menggunakan teknik analisis jalur atau path analysis. Analisis jalur (path analysis) adalah perluasan dari analisis regresi linier berganda, dimana pengembangan disini berupa penerapan variabel mediasi. Variabel mediasi merupakan variabel yang memiliki peran memediasi hubungan antara suatu variabel dengan variabel lainnya. Analisis jalur hanya dapat digunakan apabila telah memenuhi asumsi-asumsi tertentu.

Persamaan Sub-struktural 1

$$
M=\beta_{1} X_{1}+e_{1}
$$

Persamaan Sub-struktural 2

$$
\mathrm{Y}=\beta_{1} \mathrm{X}_{2}+\beta_{1} \mathrm{M}+\varepsilon_{2}
$$

Keterangan:

$$
\begin{array}{ll}
\mathrm{X} & =\text { Kepemimpinan Transformasional } \\
\mathrm{M} & =\text { Kepuasan kerja } \\
\mathrm{Y} & =\text { Komitmen Organisasional } \\
\beta_{1-} \beta_{2} & =\text { Koefisien regresi variabel } \\
\mathrm{e} & =\text { error }
\end{array}
$$

Pengujian hipotesis mediasi dapat dilakukan dengan Uji Sobel (Sobel Test). Uji sobel digunakan untuk menguji kekuatan pengaruh tidak langsung variabel Kepemimpinan Transformasional (X) ke variabel Komitmen Organisasional (Y) melalui variabel kepuasan kerja (M). Pengaruh tidak langsung Kepemimpinan Transformasional (X) terhadap variabel Komitmen Organisasional (Y) melalui variabel kepuasan kerja (M) dihitung dengan mengalikan koefisien jalur X terhadap 
I Gusti Made Indra Bhaskara, Pengaruh Kepemimpinan Transformasional...

M (a) dengan koefisien jalur M terhadap Y (b) atau ab. Standard error koefisien a dan $\mathrm{b}$ ditulis dengan $\mathrm{S}_{\mathrm{a}}$ dan $\mathrm{S}_{\mathrm{b}}$, besarnya standard error tidak langsung (indirect effect) $\mathrm{S}_{\mathrm{ab} 1}$ dihitung dengan rumus dibawah ini:

$$
\mathrm{Sab}=\sqrt{b^{2} S a^{2}+a^{2} S b^{2}+S a^{2} S b^{2}}
$$

Untuk menguji signifikansi pengaruh tidak langsung, maka dapat dilakukan dengan menghitung t dari koefisien ab dengan rumus sebagai berikut:

$$
\mathrm{Z}=\frac{a b}{S a b}
$$

Untuk mengetahui pengambilan keputusan uji hipotesa, maka dilakukan dengan cara membandingkan p- value dan alpha $(0,05)$ atau membandingkan hitung dengan $\mathrm{z}$ tabel, yang menggunakan taraf nyata 5 persen dengan daerah kritis 1,96

\section{HASIL PENELITIAN DAN PEMBAHASAN}

Data karakterisitik responden merupakan data responden yang dikumpulkan untuk mengetahui profil responden. Responden dalam penelitian ini adalah pegawai Pendapatan Daerah, sampel yang diambil dengan teknik purposive sampling berjumlah 63 orang. Karakteristik responden yang dibahas pada penelitian ini meliputi jenis kelamin, usia, status pekerjaan, jenis pekerjaan, pendidikan terakhir dan pendapatan.

Dalam penelitian sosial, variabel umur dipergunakan sebagai variabel yang mempengaruhi perilaku seseorang, misalnya saat memutuskan untuk menggunakan produk. Distribusi responden menurut umur disajikan pada Tabel 2. 
Tabel 2.

Karakteristik Responden Menurut Umur Pegawai

\begin{tabular}{cccc}
\hline No. & $\begin{array}{c}\text { Umur } \\
\text { (Tahun) }\end{array}$ & (Orang) & Jumlah \\
\hline 1. & $20-30$ & 12 & Persentase \\
2. & $31-40$ & 29 & 19,05 \\
3. & $41-50$ & 15 & 46,03 \\
4. & $>50$ & 7 & 23,81 \\
& TOTAL & $\mathbf{6 3}$ & 11,11 \\
\hline
\end{tabular}

Sumber: Data diolah, 2018

Tabel 2 menunjukkan jumlah responden berdasarkan kelompok umur. Responden dalam penelitian ini dominan memiliki umur 31-40 yaitu sebanyak 29 orang (46,03\%), rentang usia 41-50 tahun sebanyak 15 orang (23,81\%), usia 20-30 tahun sebanyak 12 orang $(19,05 \%)$ dan rentang usia $>50$ tahun sebanyak 7 orang $(11,11 \%)$.

Pendidikan responden bervariasi dari Diploma, sarjana dan pasca sarjana yang terlihat pada Tabel 3.

Tabel 3.

Karakteristik Responden Menurut Tingkat Pendidikan

\begin{tabular}{clccc}
\hline No. & & Jenis pekerjaan & Jumlah & \\
& & (Orang) & Persentase \\
\hline 2. & D1/D2/D3 & & 9 & 14,29 \\
3. & S2/S3 & TOTAL & 41 & 65,08 \\
& & 13 & 20,63 \\
\end{tabular}

Sumber: Data diolah, 2018

Tabel 3 menunjukkan karakteristik responden berdasarkan tingkat pendidikan. Jumlah responden yang yang berpendidikan Diploma sebanyak 9 orang $(14,29 \%)$, sarjana sebanyak 41 orang $(65,08 \%)$ dan pascasarjana sebanyak 13 orang $(20,63 \%)$.

Jenis kelamin responden terdiri dari laki-laki dan perempuan yang ditunjukkan pada Tabel 4 . 
Tabel 4.

Karakteristik Responden Menurut Jenis Kelamin

\begin{tabular}{|c|c|c|c|}
\hline \multirow{2}{*}{ No. } & \multirow{2}{*}{ Jenis pekerjaan } & \multicolumn{2}{|c|}{ Jumlah } \\
\hline & & (Orang) & Persentase \\
\hline 1. & Laki-laki & 24 & 38,10 \\
\hline 2. & Perempuan & 39 & 61,90 \\
\hline & TOTAL & 63 & 100 \\
\hline
\end{tabular}

Sumber: Data diolah, 2018

Tabel 4 menunjukkan karakteristik responden berdasarkan jenis kelamin.

Jumlah responden lebih dominan berjenis kelamin perempuan yaitu sebanyak 39 orang $(61,90 \%)$ dan yang berjenis kelamin laki-laki sebanyak 24 orang $(38,10 \%)$.

Pengujian data dalam penelitian ini menggunakan teknik analisis jalur (Path Analysis) yang disajikan pada tabel 5 dan tabel 6.

Tabel 5.

Hasil Analisis Jalur Sub Struktur I

\begin{tabular}{|c|c|c|c|c|c|c|}
\hline \multirow{2}{*}{\multicolumn{2}{|c|}{ Model }} & \multicolumn{2}{|c|}{$\begin{array}{l}\text { Unstandardized } \\
\text { Coefficients }\end{array}$} & $\begin{array}{l}\text { Standardized } \\
\text { Coefficients }\end{array}$ & \multirow[b]{2}{*}{$\mathbf{t}$} & \multirow[b]{2}{*}{ Sig. } \\
\hline & & B & Std. Error & Beta & & \\
\hline 1 & (Constant) & 7.666 & 1.524 & & 5.029 & .000 \\
\hline & $\begin{array}{l}\text { Kepemimpinan } \\
\text { Transformasional }\end{array}$ & .738 & .102 & 680 & 7.244 & .000 \\
\hline
\end{tabular}

Berdasarkan hasil analisis jalur substruktur 1 seperti yang disajikan pada tabel maka persamaan strukturnya adalah sebagai berikut:

$$
M=\beta_{1} X+e_{1}
$$

$$
\mathrm{M}=0,738 \mathrm{X}+\mathrm{e}_{1}
$$

Nilai $\beta_{1}$ adalah sejumlah ,738 memiliki makna bahwa kepemimpinan transformasional mempunyai pengaruh positif terhadap kepuasan kerja, hal ini menujnukkan bahwa variabel kepemimpinan transformasional yang semakin meningkat pada Badan Pendapatan Daerah Provinsi Bali maka kepuasan kerja akan meningkat sebesar 0,738 . 
Tabel 6.

Hasil Analisis Jalur Sub Struktur II

\begin{tabular}{|c|c|c|c|c|c|c|}
\hline \multirow{2}{*}{\multicolumn{2}{|c|}{ Model }} & \multicolumn{2}{|c|}{$\begin{array}{l}\text { Unstandardized } \\
\text { Coefficients }\end{array}$} & \multirow{2}{*}{$\begin{array}{c}\text { Standardized } \\
\text { Coefficients } \\
\text { Beta } \\
\end{array}$} & \multirow[b]{2}{*}{$\mathbf{t}$} & \multirow[b]{2}{*}{ Sig. } \\
\hline & & B & Std. Error & & & \\
\hline \multirow[t]{3}{*}{1} & (Constant) & 12.543 & 2.840 & & 4.416 & .000 \\
\hline & $\begin{array}{l}\text { Kepemimpinan } \\
\text { Transformasional }\end{array}$ & 669 & .218 & .389 & 3.072 & .003 \\
\hline & Kepuasan Kerja & .584 & 201 & .369 & 2.913 & .005 \\
\hline
\end{tabular}

Berdasarkan hasil análisis jalur substruktur 2 seperti yang disajikan pada tabel

6, maka didapatkan persamaan struktural sebagai berikut :

$$
\begin{aligned}
& Y=\beta_{2} X+\beta_{2} M+e_{2} \ldots \ldots \ldots \\
& Y=0,669 X+0,584 M+e_{2}
\end{aligned}
$$

Berdasarkan persamaan tersebut maka dapat disimpulkan bahwa nilai $\beta_{2}$ sebesar 0,669 memiliki arti bahwa kepemimpinan transformasional berpengaruh positif terhadap komitmen organisasional apabila kepemimpinan transformasional mengalami peningkatan maka akan diikuti oleh peningkatan komitmen organisasional sebesar 0,669.

Nilai $\beta_{3}$ sebesar 0,584 berarti kepuasan kerja berpengaruh positif dan signifikan terhadap komitmen organisasional, hal ini berarti bahwa kepuasan kerja yang meningkat akan diikuti oleh peningkatan pada komitmen organisasional sebesar 0,584 .

Perhitungan dari nilai standar eror berdasarkan model hasil analisis jalur 1 dan hasil analisis jalur 2 adalah sebagaiberikut:

$\mathrm{Pe}_{1}$

$$
\begin{aligned}
& =\sqrt{1-R^{2}} \ldots \ldots \\
& =\sqrt{1-0,462} \\
& =\sqrt{0,538} \\
& =0,733
\end{aligned}
$$


I Gusti Made Indra Bhaskara, Pengaruh Kepemimpinan Transformasional...

$$
\begin{aligned}
P\left(\mathrm{e}_{2}\right. & =\sqrt{1-R^{2}} \\
& =\sqrt{1-0,483} \\
& =\sqrt{0,517} \\
& =0,719
\end{aligned}
$$

Berdasarkan hasil perhitungan pengaruh error (Pei), maka hasil pengaruh error $\left(\mathrm{Pe}_{1}\right)$ yang didapat sebesar 0,733 dan pengaruh error $\left(\mathrm{Pe}_{2}\right)$ sebesar 0,719. Setelah menganalisis $\mathrm{e}_{1}$ dan $\mathrm{e}_{2}$ maka didapat perhitungan koefisien determinasi total sebagai berikut :

$$
\begin{aligned}
& \mathrm{R}^{2}{ }_{\mathrm{m}}=1-\left(\mathrm{e}_{1}\right)^{2}\left(\mathrm{e}_{2}\right)^{2} \ldots \ldots \ldots . . \\
& \mathrm{R}^{2}{ }_{\mathrm{m}}=1-(0,733)^{2}(0,719)^{2} \\
& \mathrm{R}^{2}{ }_{\mathrm{m}}=0,772
\end{aligned}
$$

Berdasarkan hasil perhitungan rumus koefisien determinasi total, maka diperoleh bahwa keragaman data yang dapat dijelaskan oleh model adalah sebesar

\begin{tabular}{|c|c|c|c|}
\hline Pengaruh variabel & $\begin{array}{l}\text { Pengaruh } \\
\text { langsung }\end{array}$ & $\begin{array}{l}\text { Pengaruh tidak } \\
\text { langsung }\end{array}$ & Peran Total \\
\hline $\begin{array}{l}\text { Kepemimpinan } \\
\text { transformasional }(\mathrm{X}) \rightarrow \\
\text { Kepuasan Kerja }(\mathrm{M})\end{array}$ & 0,680 & - & 0,680 \\
\hline $\begin{array}{l}\text { Kepemimpinan } \\
\text { transformasional }(\mathrm{X}) \\
\rightarrow \text { Komitmen Organisasional } \\
(\mathrm{Y})\end{array}$ & 0,389 & 0,251 & 0,440 \\
\hline $\begin{array}{l}\text { Kepuasan kerja (M) } \\
\rightarrow \text { Komitmen } \\
\text { organisasional(Y) }\end{array}$ & 0,369 & - & 0,369 \\
\hline
\end{tabular}
$77,2 \%$ atau dengan kata lain informasi yang terkandung dalam data sebesar 77,2\% dapat dijelaskan oleh model, terdiri atas variabel kepemimpinan transformasional, variabel komitmen organisasional dan variabel kepuasan kerja. Sedangkan sisanya yaitu $4,1 \%$ dijelaskan oleh variabel lain (tidak terdapat dalam model).

Tabel 7.

Pengaruh Langsung, Pengaruh Tidak Langsung dan Pengaruh Total

Analisis direct effect, indirect effect, dan total effect digunakan untuk melihat 
pengaruh kekuatan antar konstruk, baik yang secara langsung, tidak langsung maupun pengaruh totalnya. Berdasarkan pada tabel 4.9, maka dapat diartikan bahwa variabel kepemimpinan transformasional memiliki pengaruh langsung terhadap variabel kepuasan kerja sebesar 0,680, variabel kepemimpinan transformasional memiliki pengaruh secara langsung terhadap variabel komitmen organisasional sebesar 0,389 dan pengaruh secara tidak langsung sebesar 0,255. Pada variabel kepuasan kerja memiliki pengruh secara langsung terhadap variabel komitmen organisasional sebesar 0,369. Hal ini berarti bahwa pengaruh variabel kepemimpinan transformasional dengan komitmen organisasional akan meningkat apabila pengaruh tersebut terjembatani oleh variabel kepuasan kerja. Pengaruh total dalam penelitian ini menunjukkan jumlah pengaruh hubungan langsung dan tidak langsung antar variabel, dimana pengaruh total merupakan jumlah pengaruh langsung ditambah pengaruh tidak langsung.

Berdasarkan Tabel 7 menunjukkan variabel kepuasan kerja berperan sebagai variabel perantara antara kepemimpinan transformasional dengan komitmen organisasional sebesar 0,251, sehingga pengaruh total antara variabel kepemimpinan tranformasional dengan komitmen organisasional sebesar 0,440 dan sisanya dijelaskan oleh variabel lain.

Kepuasan kerja secara siginfikan memediasi hubungan antara kepemimpinan transformasional terhadap komitmen organisasional. Berdasarkan diagram jalur yang ada, maka dapat dihitung standar error koefisien a dan b ditulis dengan $S_{a}$ dan $\mathrm{S}_{\mathrm{b}}$, besarnya standar error tidak langsung (indirect effect) $\mathrm{S}_{\mathrm{ab}}$ dapat dihitung sebagai berikut : 
Keterangan :

$$
\begin{aligned}
& \mathrm{S}_{\mathrm{ab}}=\text { besarnya standar error tidak langsung } \\
& \mathrm{S}_{\mathrm{a}}=0,102 \\
& \mathrm{~S}_{\mathrm{b}}=0,201 \\
& \mathrm{a}=0,738 \\
& \mathrm{~b}=0,584 \\
& \mathrm{~S}_{\mathrm{ab}}=\sqrt{\mathrm{b}^{2} \mathrm{Sa}^{2}+\mathrm{a}^{2} \mathrm{Sb}^{2}+\mathrm{Sa}^{2} \mathrm{Sb}^{2}} \\
& \mathrm{~S}_{\mathrm{ab}}=\sqrt{0,584^{2} * 0,102^{2}+0,738^{2} * 0,201^{2}+0,102^{2} * 0,201^{2}} \\
& \mathrm{~S}_{\mathrm{ab}}=\sqrt{0,341056 * 0,010404+0,544644^{*} 0,040401+0,010404 * 0,040401} \\
& \mathrm{~S}_{\mathrm{ab}}=\sqrt{0,003548+0,022004+0,00042} \\
& \mathrm{~S}_{\mathrm{ab}}=\sqrt{0,025973} \\
& \mathrm{~S}_{\mathrm{ab}}=0,161161
\end{aligned}
$$

Untuk menguji pengaruh tidak langsung maka diperlukan untuk melakukan perhitungan nilai $\mathrm{Z}$ dari koefisien ab dengan rumus sebagai berikut:

$$
\mathrm{Z}=\frac{\mathrm{ab}}{\mathrm{S}_{\mathrm{ab}}}
$$

Keterangan:

$$
\begin{aligned}
& \text { Sab }=0,161161 \\
& a b=\text { Jalur X terhadap M (a) dengan jalur M terhadap Y (b) } \\
& Z=\frac{(0,738)(0,584)}{0,161161} \\
& Z=\frac{0,430992}{0,161161} \\
& Z=2,674296
\end{aligned}
$$

Tingkat signifikansi statistik z (p-palue) diperoleh sebesar 0,007. Ini diperoleh dari perhitungan $(1-\operatorname{NORMSDIST}(2,674)) * 2=0,007$. Karena Nilai Zvalue $>1,96$ atau $\mathrm{p}$-value $<0,05$ maka inderect effect signifikan pada taraf signifikan 5\%. Berdasarkan hasil pengujian sobel dapat disimpulkan bahwa kepuasan kerja secara siginfikan memediasi hubungan antara kepemimpinan transformasional dengan komitmen organisasional. Dalam hal ini terjadi perfect 
atau complete mediation. Pengaruh kepemimpinan transformasional terhadap komitmen organisasional pada sepenuhnya dimediasi oleh kepuasan kerja.

Berdasarkan hasil pengujian hasil hipotesis pertama, maka $\mathrm{H}_{1}$ diperoleh nilai probabilitas (sig) 0,000 dengan nilai koefisien beta sebesar 0,389 dan nilai t sebesar 3.072. Tingkat signifikansi variabel sebesar 0,000 yang berarti lebih kecil dari taraf nyata sebesar 0,05 Angka ini menunjukkan bahwa kepemimpinan transformasional memiliki pengaruh signifikan terhadap komitmen organisasional.

Berpengaruh signifikan dapat diartikan bahwa apabila kepemimpinan transformasional semakin tinggi maka komitmen organisasional dari pegawai akan semakin meningkat pula. maka hal ini dapat diartikan bahwa $\mathrm{H}_{0}$ ditolak dan $\mathrm{H}_{1}$ diterima. Hasil penelitian ini serupa dengan temuan Faharani et al. (2011), Yang, Mu-Li (2012), Tuna et al. (2011), Dunn et al. (2012), Mohammad (2012) yang menyatakan bahwa kepemimpinan transformasional berpengaruh positif dan signifikan terhadap komitmen organisasional.

Berdasarkan hasil pengujian hasil hipotesis kedua, maka $\mathrm{H}_{2}$ diperoleh nilai probabilitas (sig) 0,000 dengan nilai koefisien beta sebesar 0,680 dan nilai t sebesar 7.244. Tingkat signifikansi variabel sebesar 0,000 yang berarti lebih kecil dari taraf nyata sebesar 0,05 Angka ini menunjukkan bahwa kepemimpinan transformasional memiliki pengaruh signifikan terhadap kepuasan kerja Berpengaruh signifikan dapat diartikan bahwa apabila kepemimpinan transformasional semakin baik, maka persepsi kepuasan kerja pada pegawai akan semakin meningkat pula. maka hal ini dapat diartikan bahwa $\mathrm{H}_{0}$ ditolak dan $\mathrm{H}_{1}$ diterima. Hasil penelitian ini serupa dengan temuan, Judge dan Locke (1993) Al-Swidi et al. (2012), Athanasios dan 
I Gusti Made Indra Bhaskara, Pengaruh Kepemimpinan Transformasional...

Belias (2014) Yang dan Islam (2012) Zahari dan Shurbagi (2012) yang menyatakan bahwa kepemimpinan transformasional berpengaruh positif dan signifikan terhadap kepuasan kerja

Berdasarkan hasil pengujian hasil hipotesis ketiga, maka $\mathrm{H}_{3}$ diperoleh nilai probabilitas (sig) 0,000 dengan nilai koefisien beta sebesar 0,369 dan nilai t sebesar 2.913. Tingkat signifikansi variabel sebesar 0,000 yang berarti lebih kecil dari taraf nyata sebesar 0,05 Angka ini menunjukkan bahwa kepuasan kerja memiliki pengaruh signifikan terhadap kepuasan kerja. Berpengaruh signifikan dapat diartikan bahwa apabila kepuasan kerja meningkat maka komitmen organisasional dari pegawai akan semakin meningkat pula. maka hal ini dapat diartikan bahwa $\mathrm{H}_{0}$ ditolak dan $\mathrm{H}_{1}$ diterima. Hasil penelitian ini sesuai dengan penelitian yang dilakukan oleh Aydogdu dan Asikgil (2011), Srivastava (2013), Adekola (2012), Oyewobi et al. (2012), Fu et al. (2011) yang menyatakan bahwa kepuasan kerja berpengaruh positif dan signifikan terhadap komitmen organisasional

Berdasarkan hasil pengujian hipotesis keempat $\mathrm{H}_{4}$ diperoleh hasil nilai $\mathrm{Z}$ sebesar 2,674 yang lebih besar dari nilai Z tabel sebesar 1,96, hal ini menunjukkan bahwa $\mathrm{H}_{4}$ dapat diterima, sehingga dapat diartikan bahwa kepuasan kerja mampu memediasi pengaruh Kepemimpinan transformasional terhadap komitmen organisasional. Hasil penelitian ini juga didukung oleh pendapat dari kesuma (2016) menyatakan bahwa kepuasan kerja memediasi kepemimpinan trasfomasional terhadap komitmen organisasional

Hasil penelitian ini memberikan sebuah implikasi kepada instansi badan pendapatan daerah provinsi bali mengenai bagaimana pentingnya penerapan gaya 
kepemimpinan transformasional dan kepuasan kerja dapat memengaruhi komitmen organisasional pada pegawai Badan Pendapatan Daerah Provinsi Bali. Hasil yang diperoleh dari penelitian ini menunjukkan hubungan secara langsung antar variabel, salah satunya adalah kepemimpinan transformasional terhadap kepuasan kerja. Hal ini menunjukkan bahwa semakin baik penerapan gaya kepemimpinan transformasional pada Badan Pendapatan Daerah Provinsi Bali, maka akan berdampak baik juga bagi kepuasan kerja pegawai dari Badan Pendapatan Daerah Provinsi Bali, selanjutnya terdapat hubungan secara langsung antar variabel kepuasan kerja terhadap Komitmen Organisasional, hal ini dapat diartikan bahwa semakin baik kepuasan kerja pegawai dari Badan Pendapatan Daerah maka akan semakin meningkatkan Komitmen Organisasional pada pegawai Badan Pendapatan Daerah. Selain itu, terdapat juga pengaruh langsung pada variabel kepemimpinan transformasional terhadap komitmen organisasional. Ini dapat diartikan bahwa kepemimpinan transformasional juga memengaruhi komitmen organisasional pegawai. Implikasi penelitian ini dapat menggambarkan bahwa penerapan gaya kepemimpinan transformasional dan kepuasan kerja yang baik sangat memengaruhi Komitmen Organisasional pegawai pada Badan Pendapatan Daerah Provinsi Bali.

\section{SIMPULAN DAN SARAN}

Berdasasarkan hasil pembahasan penelitian dengan analisis jalur yang telah dilakukan, maka dapat disimpulkan bahwa kepemimpinan transformasional berpengaruh positif dan signifikan terhadap komitmen organisasional. Artinya Kepemimpinan transformasional yang semakin baik meningkatkan komitmen organisasional sehingga semakin tinggi Kepemimpinan transformasional maka 
I Gusti Made Indra Bhaskara, Pengaruh Kepemimpinan Transformasional...

semakin tinggi pula komitmen organisasional pegawai pada instansi Badan Pendapatan daerah provinsi bali.

Kepemimpinan transformasional berpengaruh positif dan signifikan terhadap kepuasan kerja. Artinya kepemimpinan transformasional yang tinggi dapat meningkatkan kepuasan kerja, sehingga semakin baik penerapan gaya kepemimpinan transformasional, maka semakin tinggi kepuasan kerja pegawai Instansi Badan pendapatan daerah Provinsi Bali.

Kepuasan kerja berpengaruh positif dan signifikan terhadap komitmen organisasional. Artinya kepuasan kerja yang semakin tinggi dapat meningkatkan komitmen organisasional, sehingga semakin tinggi kepuasan kerja maka semakin meningkat pula komitmen organisasional pada pegawai Instansi Badan pendapatan daerah Provinsi Bali

Kepuasan kerja secara siginfikan memediasi hubungan antara kepemimpinan transformasional dengan komitmen organisasional. Dengan kata lain bahwa kepemimpinan transformasional berpengaruh dalam peningkatan komitmen organisasional tapi belum secara maksimal maka dari itu harus melalui kepuasan kerja terlebih dahulu.

Saran yang dapat diberikan berkaitan dengan penelitian ini sebagai bahan pertimbangan serta masukan yang berguna bagi instansi Badan Pendapatan Daerah Provinsi Bali dimasa yang akan datang dalam meningkatkan komitmen organisasional adalah dalam meningkatkan komitmen organisasional para atasan Badan Pendapatan Daerah Provinsi Bali agar memaksimalkan penerapan gaya kepemimpinan transformasional dengan cara memberikan perhatian pada 
kebutuhan fasilitas kerja dan selalu memotivasi dalam pencapaian tujuan karena pernyataan tersebut memiliki skor terendah dengan rata-rata 3,67 dan 3,63. Sehingga mampu meningkatkan kepuasan kerja dalam mencapai target yang sudah di tentukan sehingga permasalahan tentang komitmen organisasional dari para pegawai dapat teratasi

Dalam meningkatkan komitmen organisasional para pegawai dan atasan pada Badan Pendapatan Daerah Provinsi Bali agar menjalin hubungan kerja yang baik yang satu dengan yang lainnya seperti komunikasi dalam bekerja serta meningkatkan pengawasan dari pimpinan terhadap pekerjaan yang dilakukan pegawai Badan Pendapatan Daerah Provinsi Bali karena pernyataan tersebut memiliki skor terendah dengan rata-rata yang sama yaitu 3.65. Sehingga baik pegawai maupun pimpinan dapat bekerja secara maksimal dan mencapai target yang di tentukan

Hendaknya Para Pimpinan Badan Pendapatan Daerah Provinsi Bali dalam membangun komitmen organisasional harus terlebih dahulu mewujudkan kepuasan kerja para stafnya agar terciptanya peningkatan komitmen organisasi yang tinggi.

\section{REFERENSI}

Adekola, Bola. (2012). The Impact of Organizational Commitment on Job Satisfaction: A Study of Employees at Nigerian Universities. International Journal of Human Resource Studies. 2 (2), 2126-3058.

Al-Swidi, A.K., Nawawi, M.K., and Al-Hosam, A. (2012). Is the Relationship between Employees' Psychological Empowerment and Employees' Job Satisfaction Contingent on the Transformational Leadership? A Study on the Yemeni Islamic Banks, Asian Social Science, 8(10): 130-150.

Athanasios, Koustelios., Dimitri Belias. (2014). Leadership And Job SatisfactionA Review. European Scientific Journal, 10 (8): 287-295 
I Gusti Made Indra Bhaskara, Pengaruh Kepemimpinan Transformasional...

Aydogdu, Sinem., Baris Asikgil. (2011). An Empirical Study of the Relatinship Among Job Satisfaction, Organizational Commitment and Turnover Intention. Internationl Review of Management and Marketing, 1 (3): 43-53.

Azeem, S.M. (2010). Job Satisfaction and Organizational Commitment among Employees in the Sultanate of Oman, Journal of Psychology, 1(6), pp. 295299.

Bass, Bernard., Avolio., Dong Jung. (1999). Re-Examining The Component Of Transformational And Transactional Leadership Using Of Multifactor Leadership Questionnaire. Journal Of Occupational And Organizatonal Psychology. 71(1): 441-462.

Cavazotte, Flavia., Valter Moreno. dan Mateus Hickmann. (2012). Effects of Leader Intelligence, Personality and Emotional Intelligence on Transformational Leadership and Managerial Performance. The Leadership Quarterly. 23(4): 443-455.

Djastuti, Indi. (2011). Pengaruh Karakteristik Pekerjaan Terhadap Komitmen Organisasi Karyawan Tingkat Managerial Perusahaan Jasa Konstruksi Di Jawa Tengah. Jurnal Bisnis Dan Akuntansi. 13(1): 1-19.

Dunn, M.W., Dastoor, B. and Sims, R.L. (2012). Transformational Leadership and Organizational Commitment: A Cross-Cultural Perspective, Journal of Multidisciplinary Research, 4(1): 45-59.

Faharani, M., Taghadosi, M., and Behboudi, M. (2011). An Exploration f the Relationship between Transformational Leadership and Organizational Commitment: The Moderating Effect of Emotional Intelligence: Case Study in Iran. International Business Research, 4(4): 211-217.

Fu, Weihui, Satish P. Deshpande dan Xiao Zhao. (2011). The Impact of Ethical Behavior and Facets of Job Satisfaction on Organizational Commitment of Chinese Employees. Journal Business Ethics. 104(9): 537-543.

Joo, Baek-Kyoo, Hea J. Y., and Chang-Wook Jeung. (2012). The effects of core self-evaluations and transformational leadership on organizational commitment. Leadership \& Organization Development Journal, 33(6): 564582.

Judge, T. A., \& Locke, E. (1993). Effect of Dysfunctional Thought Processes on Subjective Well-Being and Job Satisfaction. Journal of Applied Psychology, 78 (3) : 475-490.

Kesuma, I Gede Anggi Wira. (2016). Pengaruh Kepemimpinan Transformasional Terhadap Komitmen Organisasional Dengan Mediasi Organizational Citizenship Behavior Dan Kepuasan Kerja. E-Jurnal Manajemen Unud, 5 (6): 3677-3705 
Maulizar. Said Musnadi dan Muklis Yunus. (2012). Pengaruh Kepemimpinan Transaksional dan Transformasional Terhadap Kinerja Karyawan Bank Syariah Mandiri Cabang Banda. Jurnal Manajemen Pascasarjana Universitas Syiah Kuala. 1(1): 58-65.

Mohamed, Sheik Anisa. (2012). Relationship Between Organizational Commitment and Organizational Citizenship Behavior. The IUP Journal of Organizational Behavior, 9(3): 122-143.

Mohammad, M. S. (2012). Transformational Leadership and Employees' Job Satisfaction and Commitment: A Structural Equation Investigation. Journal of American Science, 8 (7), 11-19.

Munawaroh. (2011). Pengaruh Gaya Kepemimpinan Transformasional dan Transaksional Terhadap Kinerja Guru. Jurnal Ekonomi Bisnis. 16(2): 4-16

Nawab, S \& Komal K. B. (2011). Influence of employee compensation on organizational commitment and job satisfaction: a case study of educational sector of Pakistan. International Journal of Business and Social Science. 2 (8): $45-50$

Northouse, Peter. (2013). Kepemimpinan Edisi Keenam. Jakarta: PT. Indeks.

Oyewobi, Luqman Oyekumle., Bolaji Suleiman, \& Abubakar Mhammad-Jamil. 2012. Job Satisfaction and Job Commitment : A Study of Quantity Surveyors in Nigerian Public Service. International Journal of Business and Management, 7 (5): 67-80

Permadi, I Made Yudi. (2017). Pengaruh Kompensasi, Budaya Organisasi Dan Lingkungan Kerja Terhadap Kepuasan Kerja Karyawan. E-Jurnal Manajemen Unud, 6 (1):521-549

Rae, Kirsten. (2013). Perceptions Of Empowerment And Commitment Affect Job Satisfaction : A Study Of Managerial Level Effects. Accounting, Accountability \& Performance, 18(1):123-140

Sakiru, Oladipo Kolapo, Jefrey Lowrence Dsiva, Jamilah Othman, and Adekanye Temitope Busayo. (2013). Leadership Style and Job Satisfaction among Employees in Small and Medium Enterprises. International Journal of Business and Management, 8(13):34-41.

Shahhosseini, Mohammad., Abu, Daud, Silong. dan Ismi, Arif, Ismaill. (2013). Relationship Between Transactional, Transformational Leadership Style, Emotional Intelligence and Job Performance. Journal of Arts, Science \& Commerce. Vol 4 (1):15-22. 
I Gusti Made Indra Bhaskara, Pengaruh Kepemimpinan Transformasional...

Srivastava, Shalini. (2013). Job Satisfaction and Organizational Commitment Relationship: Effect of Personality Variables. Vision .17 (2): 159-167.

Surbakti. (2013). Analisis Pengaruh Kepemimpinan Transformasional dan Motivasi terhadap Kinerja Karyawan: Studi pada PT. Kereta Api Indonesia Daop IV Semarang. Jurnal Fakultas Ekonomi Unniversitas Diponogoro Semarang, 1(1): 55-67.

Tuna, M., Ghazzawi, I., Tuna, A.A., and Çatir, O. (2011). Transformational Leadership and Organizational Commitment: The Case of Turkey's Hospitality Industry, S.A.M. Advanced Management Journal, 76(3): 10-25.

Voon, M.L., M.C. L, K.S. Ngui1., and N.B. Ayob. (2011). The Influence Of Leadership Styles On Employees' Job Satisfaction In Public Sector Organizations In Malaysia. International Journal of Business, Management and Social Sciences, 2(1): 24-32.

Warrick, D D. (2011). The Urgent Need for Skilled Transformational Leaders: Integrating Transformational Leadership and Organization Development. Journal of Leadership, Accountability and Ethics. 8(5): 100-120.

Wibawa, I Made Artha. (2015). Pengaruh Kepuasan Kerja terhadap Turnover Intention dengan Komitmen organisasional sebagai variabel Intervening pada PT. Autobagus Rent Car Bali. E-Jurnal Manajemen Unud 4(4): 11001118

Yang, Mu-Li. (2012). Transformational Leadership and Taiwanese Public Relations Practitioner' Job Satisfaction and Organizational Commitment. Journal of Social Behavior and Personality, 40(1): 31-46.

Yang, Yi-Feng, and Islam, M. (2012). The Influence of Iransformational Leadership on Job Satisfaction: The Balanced Scorecard Perspective, Journal of Accounting \& Organizational Change, 8(3): 386-402.

YU Bo. (2013). The Influence Study of Transformational Leadership in University on Teacher's Organizational Commitment: The Construction and Verification of a Theoretical Model. Canadian Social Science , 9(4): 126-137

Yukl, G. (2010). Kepemimpinan Dalam Organisasi. Edisi Indonesia. Jakarta: Penerbit PT Indeks.

Zahari, I., and Shurbagi, A. (2012). The Effect of Organizational Culture and the Relationship between Transformational Leadership and Job Satisfaction inPetroleum Sector of Libya, International Business Research, 5(9): 89-975 